\title{
Kinerja dari Prototipe Robot Visual Pengumpul Sampah Perairan dengan Remote Control menggunakan Telemetri
}

\author{
Faiz Sulistyawan ${ }^{1}$, Sri Waluyanti ${ }^{2}$ \\ ${ }^{1,2}$ Program Studi Teknik Elektronika Fakultas Teknik Universitas Negeri Yogyakarta \\ E-mail: faiz.sulistyawan@gmail.com
}

\begin{abstract}
The making of prototype robot waste water collection aims to know the performance itself. The prototype of the Aquatic Waste Collection Robot is designed to float and clean trash in remote controlled waters. The main control drives a series of DC brushless motors to drive while the MG995 servo motor drives a rudder or defender. The device is also equipped with a camera as a medium to see the condition of the robot directly or in real time which will be displayed on the monitor screen. The camera and screen are connected to a telemetry circuit consisting of a transmitter and receiver with a frequency of $5.8 \mathrm{GHz}$, and a Li-Po battery as a source of robot power supply. The results of prototype testing of water garbage collection robots have been carried out in Embung Langensari Yogyakarta with a depth of 2-3 meters and an area of $5890 \mathrm{~m} 2$, the robot can go with a maximum speed of $0.3 \mathrm{~m} / \mathrm{s}$ with or without the garbage load. Garbage nets used with a capacity of 20 liters. Robots can maneuver to turn right or left with a rudder. In the garbage collection process, this robot can collect relatively small waste.
\end{abstract}

Keywords: Remote Control, First Person Viewer, Prototype, Water Garbage Collection Robot

\begin{abstract}
ABSTRAK
Pembuatan Prototipe Robot Pengumpul Sampah Perairan bertujuan untuk mengetahui unjuk kerjanya. Prototipe Robot Pengumpul Sampah Perairan dirancang dapat mengapung dan membersihkan sampah pada perairan dikendalikan dengan remote control. Kendali utama menggerakan rangkaian motor brushless DC agar dapat melaju sedangkan motor servo MG995 sebagai penggerak rudder atau pembelok. Perangkat juga dilengkapi dengan kamera sebagai media untuk melihat kondisi robot secara langsung atau real time yang akan di tampilkan pada layar monitor. Kamera dan layar tersebut dihubungkan dengan rangkaian telemetri yang terdiri dari transmitter dan receiver dengan frekuensi $5.8 \mathrm{GHz}$, serta baterai Li-Po sebagai sumber catu daya robot. Hasil pengujian prototipe robot pengumpul sampah perairan telah dilaksanakan di Embung Langensari Yogyakarta dengan kedalaman 2-3 meter dan luas $5.890 \mathrm{~m} 2$, robot dapat melaju dengan kecepatan maksimal 0,3 m/s dengan ataupun tanpa beban sampah. Jaring sampah yang digunakan berkapasitas 20 liter. Robot dapat melakukan manuver untuk membelok ke kanan atau ke kiri dengan rudder. Pada proses pengumpulan sampah, robot ini dapat mengumpulkan sampah yang relatif kecil.
\end{abstract}

Kata kunci: Remote Control, First Person Viewer, Prototype, Robot Pengumpul Sampah Perairan

\section{PENDAHULUAN}

Indonesia merupakan negara kepulauan yang luas. Hal tersebut menjadikan Indonesia sebagai negara yang kaya akan tempat pariwisata terutama di bagian wilayah pesisir, contohnya pantai. Namun, pada beberapa pantai banyak ditemukan polusi. Polusi yang paling banyak ditemukan ialah berupa limbah padat, seperti logam, plastik, dan kertas. Sampah plastik memiliki sifat yang sulit terdegradasi di alam, sehingga menjadi penyumbang limbah terbesar yang dapat mengakibatkan keseimbangan alam rusak [1]. Hasil riset mengenai fakta sampah plastic dilaut dari grup penelitian Jambeck menyebutkan bahwa Indonesia sebagai peringkat dua penyumbang sampah plastik ke lautan di dunia sebanyak 
187,2 juta ton [2]. Muhammad Reza Cordova menyatakan bahwa terdapat 1,71 buah sampah plastik setiap satu meter persegi di pantai Indonesia. Nilai tertinggi adalah di pantai Sulawesi dengan rerata 2,35 buah sampah plastik per meter persegi dan di pantai Jawa dengan rerata 2,11 buah sampah plastik per meter persegi. Berdasarkan perhitungan kasar dan asumsi sederhana, sampah plastik di laut yang diproduksi orang Indonesia sendiri diprediksi mencapai 100.000 hingga 400.000 ton per tahun [3].

Keberadaan sampah plastik dilaut mengalami peningkatan melalui penguraian menjadi semakin kecil (mikroplastik) akibat aktivitas sinar UV dan abrasi [4]. Penampakan mikroplastik yang sangat kecil menyerupai makanan bagi biota laut [5]. Dilain pihak, salah satu sifat yang dimiliki mikroplastik adalah dapat menyerap racun bahan-bahan kimia di sekitarnya [6]. Hal tersebut akan berdampak pada rantai makanan. Tambahan, selain bahaya saat dikonsumsi, banyak hewan laut yang terjerat sampah plastik [7]. Mengingat hal tersebut, maka diperlukan upaya untuk membersihkan sampah plastik.

Pemerintah telah melakukan upaya untuk membersihkan pantai dari sampah, salah satunya dengan mengeluarkan Peraturan Presiden (Perpres) Nomor 97 tahun 2017 tentang Kebijakan dan Strategi Nasional Pengelolaan Sampah [8]. Beberapa komunitas pecinta lingkungan di berbagai provinsi juga telah membentuk sebuah gerakan untuk membersihkan pantai. Namun dibutuhkan waktu yang sangat lama dan sangat menguras tenaga manusia untuk bisa merasakan dampak positif dari berbagai upaya tersebut.

Pengembangan prototype robot observasi bawah air sebelumnya telah dikembangkan [9]. Robot yang bergerak di perairan lainnya digunakan untuk operasi pencarian [10]. Penelitian tersebut terbatas pada pergerakan dan pengaplikasian yang belum mengarah untuk pembersihan sampah plastik. Oleh karena itu, diperlukan suatu alat berupa robot yang dapat membantu membersihkan sampah khususnya di daerah pantai secara cepat dam efisien. Robot ini dirancang menggunakan remote control dengan frekuensi 2,4 GHz dan dilengkapi penggerak motor brushless DC. Selain itu, terdapat kamera untuk melakukan monitoring secara jarak jauh, baterai sebagai sumber catu daya, dan jaring untuk menampung sampah.

\section{METODE}

Pembuatan robot pengumpul sampah perairan ini terdiri dari dua bagian yaitu bagian mekanik dan elektronika. Bagian mekanik merupakan bagian yang meliputi desain 3D dan mekanisme pembuatan. Bagian elektronika yang meliputi sistem - sistem yang berkaitan dengan rangkain seperti rangkain pada board serta komponen - komponen elektronika. Pada bagian mekanik, rancangan kerangka diperlukan untuk membangun mekanik robot dengan ukuran dan dudukan komponen agar dapat presisi dan pergerakan robot dapat berjalan sempurna tanpa mengalami kendala. Pada perancangan mekanik komponen yang akan digunakan yaitu pipa paralon, kayu triplek, plat alumunium, dan plat besi. Bagian badan robot menggunakan bahan kayu triplek dengan panjang $28 \mathrm{~cm}$, lebar atap 14 $\mathrm{cm}$, tinggi $8 \mathrm{~cm}$ sedangkan untuk pengapung dibuat dengan bahan pipa paralon dengan panjang $40 \mathrm{~cm}$ dan berdiameter $9 \mathrm{~cm}$.

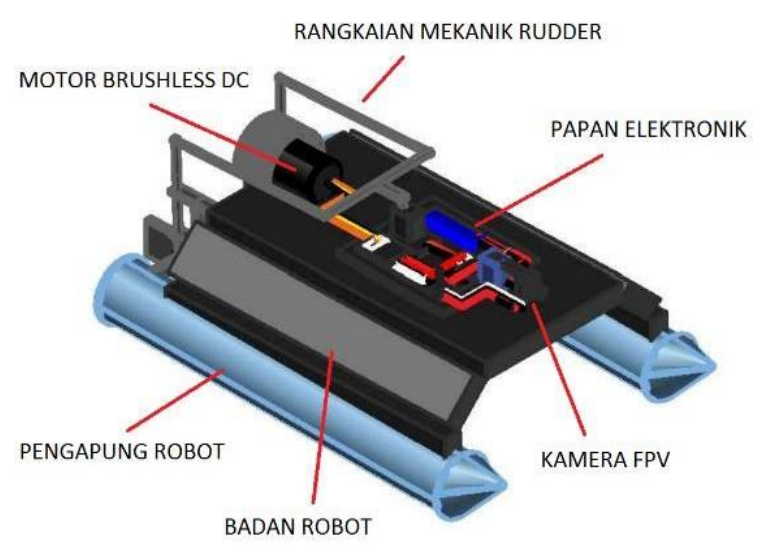

Gambar 1. Desain 3D robot

Rancangan 3D yang dapat dilihat pada Gambar 1 diperlukan sebagai acuan dalam membangun suatu alat, dalam hal ini robot 
amfibi pengintai. Terdapat beberapa part untuk kerangka robot dan part untuk robot lengan yang kemudian dilakukan perakitan menjadi satu kesatuan mekanik.

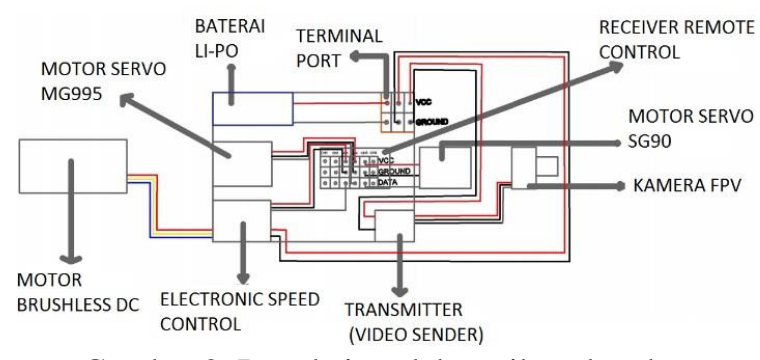

Gambar 2. Rangkaian elektronik pada robot

Pada Gambar 2 terdapat beberapa komponen yang terpasang pada robot salah satunya receiver, receiver ini akan menangkap sinyal yang diberikan oleh transmitter sehingga dapat mengontrol ESC dan servo secara elektronis sesuai keinginan. Terdapat 3 kanal yang digunakan pada receiver yaitu kanal 2,3, dan 4. Setiap kanal memiliki 3 pin yaitu VCC, ground, dan data. Kanal 2 tersambung dengan motor servo SG90, kanal 3 tersambung pada ESC untuk menggerekkan motor brushless DC, dan kanal 4 tersambung pada motor servo MG995. Terdapat kamera FPV yang berfungsi sebagai perekam kondisi visual robot secara langsung yang terhubung secara wireless atau tanpa kabel pada transmitter video sender berfrekuensi 5,8 GHz. Rangkaian ini juga terhubung baterai Li-Po sebagai sumber catu daya.

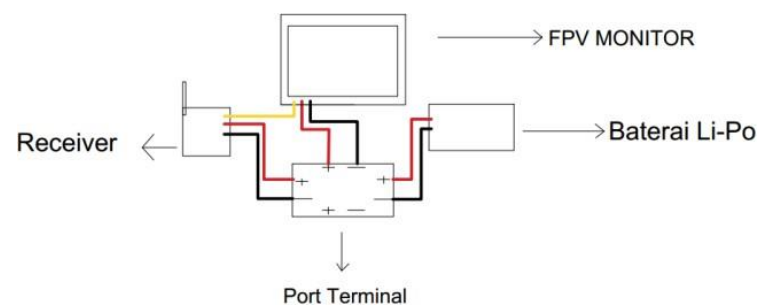

Gambar 3. Rangkaian monitor FPV

Pada Gambar 3 terdapat beberapa komponen yang terpasang pada remote control. Receiver pada Gambar 3 merupakan receiver yang terhubung tanpa kabel dengan transmitter video sender pada Gambar 2 yang berfungsi sebagai penerima hasil rekaman yang akan ditampilkan oleh monitor FPV. Rangkaian ini memiliki baterai Li-Po sebagai sumber catu daya.

\section{HASIL DAN PEMBAHASAN}

Pengujian terhadap alat dilakukan untuk mengetahui kinerja baik masing - masing komponen dan keseluruhan alat. Hasil dari pengujian alat tersebut diharapkan mampu mendapatkan data yang valid dan mengetahui apakah alat sudah bekerja sesuai dengan yang diharapkan. Pengujian fungsional merupakan pengujian yang dilakukan pada setiap bagian dari masing-masing alat yang digunakan pada proyek akhir ini. Tujuan dari pengujian ini untuk mengetahui perangkat yang digunakan telah bekerja dengan fungsinya.

Pengujian daya baterai digunakan untuk menguji apakah dua baterai Li-Po yang digunakan bekerja dengan benar atau tidak, pengujian ini dilakukan dengan mengukur tegangan dan durasi dari kedua baterai Li-Po tersebut. Tabel pengujian daya baterai pada robot terdapat pada Tabel 1 dan pengujian daya baterai pada monitor FPV terdapat pada Tabel 2 .

Tabel 1. Tabel pengujian daya baterai Li-Po pada robot

\begin{tabular}{ccc}
\hline \multirow{2}{*}{ No. } & \multicolumn{2}{c}{ Indikator } \\
& Tegangan (Volt) & Waktu (Durasi) \\
\hline 1. & 12,2 & 1 menit \\
2. & 10,8 & 2 menit \\
3. & 10,1 & 3 menit \\
4. & 9,2 & 4 menit \\
5. & 8,0 & 5 menit \\
\hline
\end{tabular}

Tabel 2. Tabel pengujian daya baterai Li-Po pada monitor FPV

\begin{tabular}{ccc}
\hline \multirow{2}{*}{ No. } & \multicolumn{2}{c}{ Indikator } \\
& Tegangan (Volt) & Waktu (Durasi) \\
\hline 1. & 12,1 & 1 menit \\
2. & 11,9 & 2 menit \\
3. & 11,6 & 3 menit \\
4. & 11,1 & 4 menit \\
5. & 10,3 & 5 menit \\
\hline
\end{tabular}

Berdasarkan hasil pengukuran daya baterai waktu operasi kerja robot adalah sekitar 5 menit. Setiap kelipatan 1 menit tegangan baterai pada robot berkurang sekitar 1 volt dari 
12,2 volt hingga 8,0 volt, sedangkan tegangan baterai pada monitor FPV berkurang sekitar 0,3 volt dari 12,1 volt hingga 10,3 volt, hal itu disebabkan karena karakteristik baterai Li-Po yang secara periodik tegangan akan terus berkurang sesuai dengan durasi waktu robot beroperasi.

Pengujian Sudut Rudder atau Kendali Kapal digunakan untuk mengukur sudut rudder atau kendali kapal yang digerakan dengan motor servo MG995 kemudian dibandingkan dengan putaran joystick serta mengukur tegangan keluaran pada motor servo. Tabel pengujian sudut rudder ditunjukkan pada Tabel 3.

Tabel 3. Tabel pengujian sudut rudder.

\begin{tabular}{lcccc}
\hline No Arah & Putaran & $\begin{array}{c}\text { Sudut } \\
\text { putaran } \\
\text { joystick } \\
\text { joystick }\end{array}$ & $\begin{array}{c}\text { Tegangan keluaran } \\
\text { motor } \\
\text { servo }\end{array}$ \\
\hline 1. Kanan & $50 \%$ & $21^{\circ}$ & $103.8 \mathrm{mV}$ \\
2. Kanan & $100 \%$ & $43^{\circ}$ & $121.7 \mathrm{mV}$ \\
3. Kiri & $50 \%$ & $24^{\circ}$ & $103.4 \mathrm{mV}$ \\
4. Kiri & $100 \%$ & $41^{\circ}$ & $122.2 \mathrm{mV}$ \\
\hline
\end{tabular}

Berdasarkan data tersebut terdapat putaran sudut rudder yang berbeda pada saat kondisi rudder berputar ke kanan dan kekiri. Ketika joystick digerakan kekanan atau kekiri $50 \%$ terdapat perbedaan sudut sebesar 3o sedangkan joystick digerakan kekanan atau kekiri $100 \%$ terdapat perbedaan sudut sebesar $2 \mathrm{o}$, hal ini disebabkan oleh rangkaian mekanik rudder yang kurang presisi. Pada pengukuran tegangan keluaran motor servo menggunakan multimeter dengan tegangan yang meningkat mengacu pada besarnya putaran servo.

Tabel 4. Tabel pengujian sudut pandang kamera FPV

\begin{tabular}{lcccc}
\hline No Arah & Putaran & $\begin{array}{c}\text { Sudut } \\
\text { putaran } \\
\text { motor } \\
\text { sorvo }\end{array}$ & $\begin{array}{c}\text { Tegangan keluaran } \\
\text { motor } \\
\text { servo }\end{array}$ \\
\hline 1. Kanan & $50 \%$ & $26^{\circ}$ & $68.1 \mathrm{mV}$ \\
2. Kanan & $100 \%$ & $45^{\circ}$ & $86.6 \mathrm{mV}$ \\
3. & Kiri & $50 \%$ & $25^{\circ}$ & $67.8 \mathrm{mV}$ \\
4. & Kiri & $100 \%$ & $45^{\circ}$ & $87 \mathrm{mV}$ \\
\hline
\end{tabular}

Tabel 4 merupakan hasil pengujian sudut pandang kamera FPV. Pengujian sudut pandang kamera FPV digunakan untuk mengukur pandangan secara horisontal robot menggunakan kamera yang digerakkan dengan motor servo SG90 yang dibandingkan dengan sudut putaran joystick serta mengukur tegangan keluaran pada motor servo. Berdasarkan data pada Tabel 4 terdapat putaran sudut pandang yang berbeda. Ketika joystick digerakan kekanan atau kekiri $50 \%$ terdapat perbedaan sudut sebesar 1o, hal ini disebabkan oleh rangkaian mounting kamera yang kurang presisi. Pada pengukuran tegangan keluaran motor servo menggukan multimeter dengan tegangan yang meningkat mengacu pada besarnya putaran servo.

Pengujian laju robot digunakan untuk mengukur seberapa cepat robot dapat melaju dengan mengacu pada kondisi throttle yang sudah ditentukan yaitu 25\%, 50\%, 75\%, 100\% dengan robot membawa beban sampah dan tidak membawa beban sampah. Tabel pengujian laju robot terdapat pada Tabel 5 .

Tabel 5. Tabel pengujian laju robot.

\begin{tabular}{cccc}
\hline No. & $\begin{array}{c}\text { Throttle } \\
(\%)\end{array}$ & $\begin{array}{c}\text { Kecepatan } \\
\text { membawa sampah }\end{array}$ & $\begin{array}{c}\text { Kecepatan tanpa } \\
\text { membawa sampah }\end{array}$ \\
\hline 1. & $25 \%$ & $0,04(\mathrm{~m} / \mathrm{s})$ & $0,02(\mathrm{~m} / \mathrm{s})$ \\
2. & $50 \%$ & $0,08(\mathrm{~m} / \mathrm{s})$ & $0,08(\mathrm{~m} / \mathrm{s})$ \\
3. & $75 \%$ & $0,1(\mathrm{~m} / \mathrm{s})$ & $0,1(\mathrm{~m} / \mathrm{s})$ \\
4. & $100 \%$ & $0,3(\mathrm{~m} / \mathrm{s})$ & $0,3(\mathrm{~m} / \mathrm{s})$ \\
\hline
\end{tabular}

Berdasarkan pengujian pada Tabel 5, kecepatan robot melaju diuji dengan 4 kondisi throttle mengacu pada dorongan joystick, yaitu $25 \%, 50 \%, 75 \%, 100 \%$. Dari hasil pengujian laju robot dapat disimpulkan bahwa, laju robot kecepatannya relatif sama antara robot tanpa beban sampah atau dengan beban yaitu $0,3 \mathrm{~m} / \mathrm{s}$ pada kondisi throttle $100 \%$ hingga $0,04 \mathrm{~m} / \mathrm{s}$ pada kondisi throttle $25 \%$, hal ini disebabkan karena bobot sampah yang dapat ditampung robot relatif kecil atau ringan.

Pengujian kinerja ini bertujuan untuk mengetahui jenis sampah yang bisa ditangkap oleh robot serta berapa banyak sampah yang dapat dikumpulkan. Pada proses pengujian ini dilakukan pada lokasi daerah perairan seperti waduk sebagai sampel pengambilan data. Pengujian kinerja alat ditunjukkan pada Tabel 6. 
Tabel 6. Tabel kinerja robot.

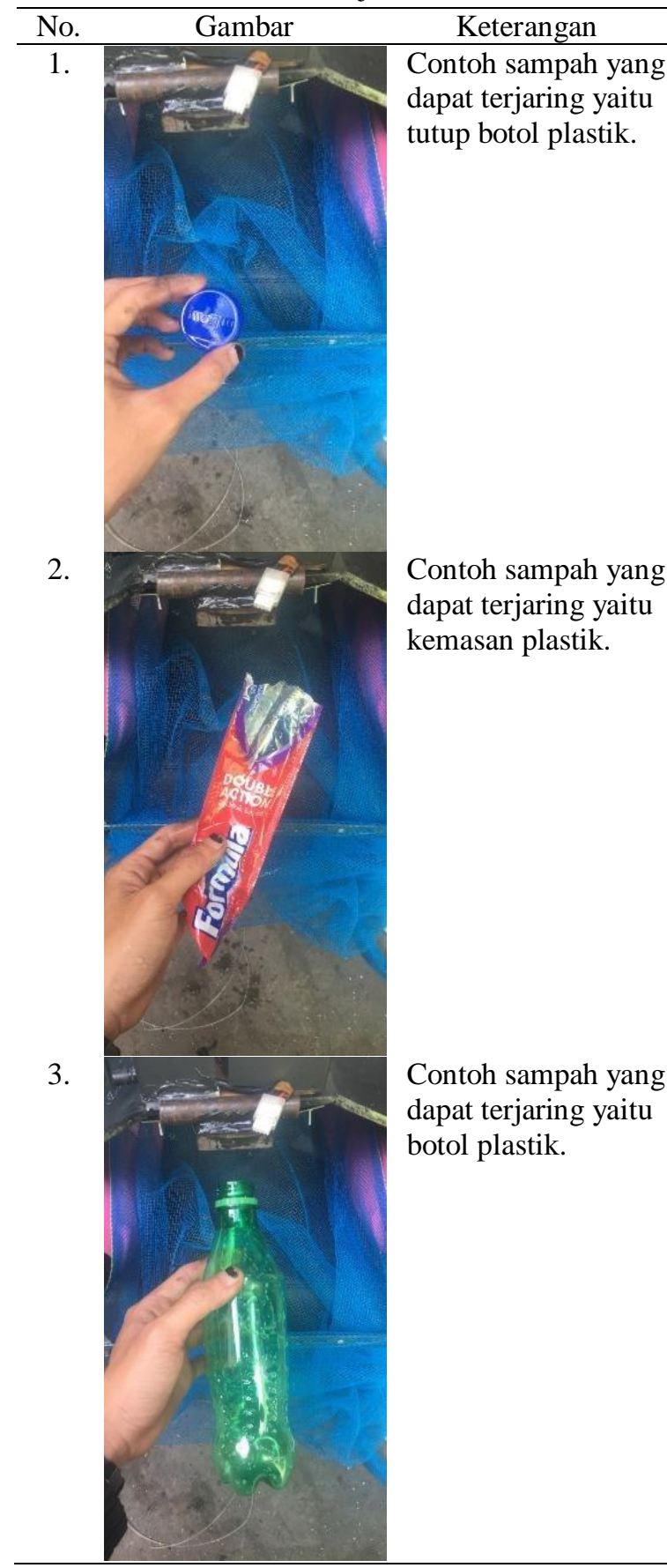

Sesuai dengan hasil pengujian pada Tabel 6 alat ini berfungsi sesuai dengan yang diharapkan. Pengujian ini dilakukan dengan cara mengumpulkan sampah menggunakan robot yang dilengkapi jaring berukuran $40 \times 60 \mathrm{~cm}$. Uji kinerja alat ini dilakukan dilokasi tertentu, sebagai sampel pengambilan data alat ini diuji di Embung Langensari, Yogyakarta dengan kedalaman air 2-3 meter dan luas $5.890 \mathrm{~m} 2$ [11]. Lokasi ini dipilih karena kondisi air yang relatif tenang. Robot ini dapat mengumpulkan sampah dengan berbagai macam jenis, salah satunya sampah plastik.

\section{SIMPULAN}

Prototipe robot pengumpul sampah perairan yang dikembangkan merupakan robot pembantu untuk membersihkan sampah perairan. Pembuatan alat ini meliputi mekanik dan elektronik. Mekanik robot menggunakan 3 bahan utama, yaitu kayu, pipa paralon, dan besi plat yang kemudian semua bagian tersebut disatukan sesuai dengan desain 3D pada perancangan mekanik. Selain pembuatan mekanik juga terdapat pembuatan elektronik yang terdiri dari joystick yang terhubung pada receiver dengan frekuensi $2.4 \mathrm{Ghz}$ berfungsi sebagai pusat kendali dari robot, dimana joystick ini dapat menggerakkan motor brushless DC yang diatur kecepatannya menggunakan electronic speed control (ESC) agar robot dapat berjalan, kemudian motor servo SG90 untuk menggerakkan kamera secara horizontal, dan motor servo MG995 agar robot dapat membelok ke kanan atau ke kiri. Selain itu alat ini dilengkapi dengan kamera FPV sebagai media visual secara real time kemudian akan ditampilkan pada layar FPV yang terpasang pada joystick, kedua komponen ini terhubung melalui rangkaian telemetri yang terdiri dari transmitter dan receiver berfrekuensi $5.8 \mathrm{GHz}$.

Unjuk kerja dari prototipe robot pengumpul sampah perairan berdasarkan hasil pengujian yang telah dilaksanakan di Embung Langensari Yogyakarta dengan kedalaman 2- 3 meter dan luas $5.890 \mathrm{~m} 2$, robot dapat melaju dengan kecepatan maksimal $0,3 \mathrm{~m} / \mathrm{s}$ tanpa beban sampah atau dengan beban sampah dan robot dapat melakukan manuver untuk membelok kanan atau kiri dengan rudder. Pada proses pengumpulan sampah, robot ini dapat mengumpulkan sampah dengan ukuran yang relatif kecil dari jaring yang berukuran 40x60 $\mathrm{cm}$.

Prototipe robot pengumpul sampah memiliki keterbatasan dalam sistem kerjanya antara lain: (1) kapasitas baterai yang rendah 
sehingga robot tidak dapat bertahan lama ketika beroprasi; (2) laju dan kekuatan robot masih kurang sehingga kemampuan laju robot masih belum memuaskan; (3) manuver robot untuk membelok kanan atau kiri masih kurang memuaskan; dan (4) jaring dengan ukuran yang kecil membuat sampah yang dapat ditampung sedikit. Jika direalisasikan sebagai alat sebenarnya, perlu adanya modifikasi sebagai berikut: (1) menggunakan baterai dengan kapasitas yang lebih tinggi; (2) menggunakan motor DC dengan spesifikasi RPM dan torsi yang lebih tinggi serta ukuran propeller yang lebih besar; (3) menggunakan rangkaian mekanik rudder dengan rancangan yang perisi; dan (4) menggunakan jaring dengan ukuran yang lebih besar.

\section{DAFTAR PUSTAKA}

[1] Asia and M. Z. Arifin, "Dampak Sampah Plastik bagi Ekosistem Laut," Bul. Matric, vol. 14, no. 1, pp. 44-48, 2017.

[2] J. R. Jambeck, R. Geyer, C. Wilcox, T. R. Siegler, M. Perryman, A. Andrady, R. Narayan, and K. L. Law, "Plastic waste inputs from land intothe ocean," Science (80-. )., vol. 347, no. 6223, pp. 768-771, 2015.

[3] L. Jemadu, "LIPI: Tiap 1 Meter Persegi Pantai Indonesia, Ada 1,7 Sampah Plastik," Suara.com, 2018. [Online]. Available: https://www.suara.com/tekno/2018/11/30/1739 52/lipi-tiap-1-meter-persegi-pantai-indonesiaada-17-sampah-plastik.
[4] K. L. Law and R. C. Thompson, "Microplastics in the seas," Science (80-. )., vol. 345, no. 6193, pp. 144-145, 2014.

[5] A. Lusher, M. McHugh, and R. Thompson, "Occurrence of microplastics in the gastrointestinal tract of pelagic and demersal fish from the English Channe," Mar. Pollut. Bull., vol. 67, pp. 94-99, 2013.

[6] S. A. Carr, J. Liu, and A. G. Tesoro, "Transport and fate of microplastic particles in wastewater treatment plants," Water Res, vol. 91, pp. 174$182,2016$.

[7] G. L. Widyaningrum, "Perilaku Manusia dan Dampak Sampah Plastik yang Menewaskan Hewan Laut," National Geographic Indonesia, $2018 . \quad$ [Online]. Available: https://nationalgeographic.grid.id/read/1312443 53/perilaku-manusia-dan-dampak-sampahplastik-yang-menewaskan-hewan-laut?page $=$ all.

[8] K. S. N. RI, Peraturan Presiden (PERPRES) Nomor 97 Tahun 2017 tentang Kebijakan dan Strategi Nasional Pengelolaan Sampah Rumah Tangga dan Sampah Sejenis Sampah Rumah Tangga. 2017.

[9] F. Irawan and A. Yulianto, "Perancangan Prototype Robot Observasi Bawah Air dan Kontrol Hovering Menggunakan Metode Pid Control," J. Sains dan Inform., vol. 1, no. 1, pp. 63-70, 2015.

[10]M. Iqbal, "Remote Control Rescue Robotic Boat for Search Operation," Int. J. Comput. Eng. Inf. Technol., vol. 8, no. 6, pp. 96-99, 2016.

[11]B. L. H. D. I. Yogyakarta, Dokumen Informasi Kinerja Pengelolaan Lingkungan Hidup Daerah Istimewa Yogyakarta (DIY). Yogyakarta: BLH DIY, 2016. 